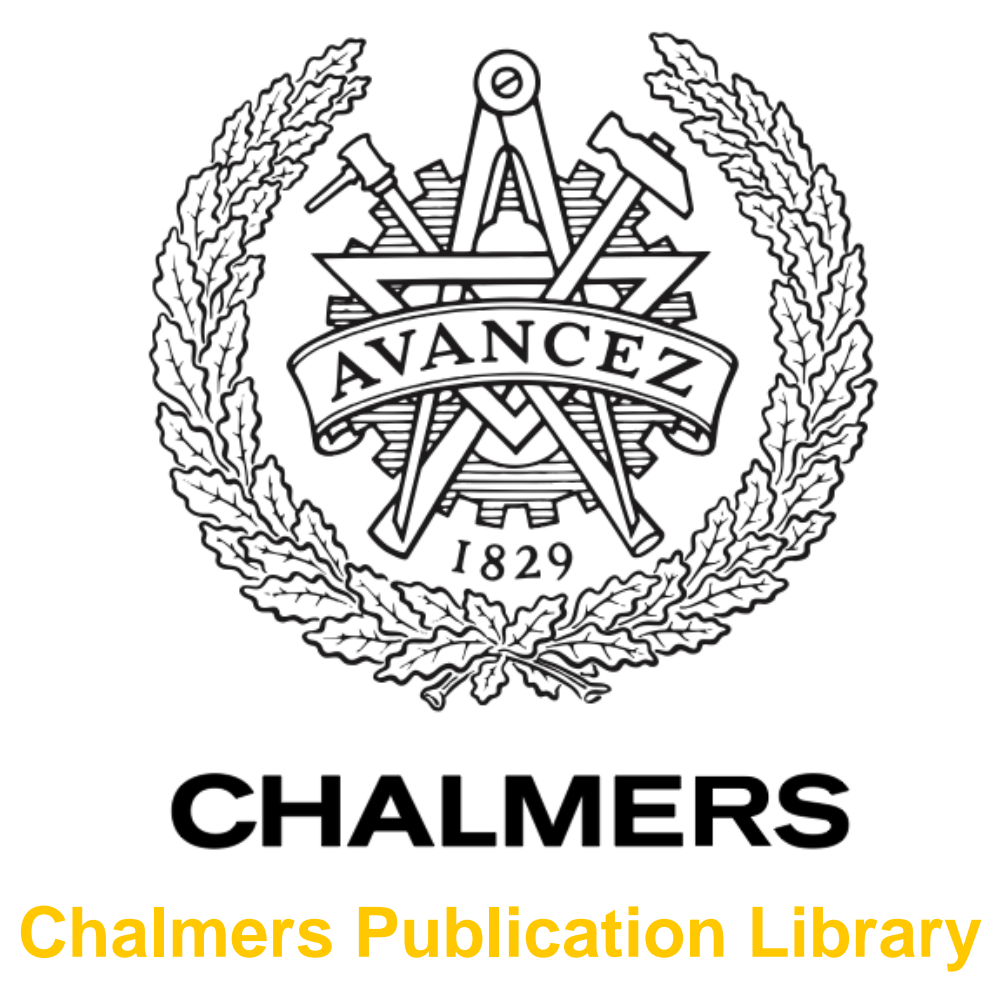

\title{
V-band high efficiency corporate-fed $8 \times 8$ slot array antenna with ETSI class II radiation pattern based on gap technology
}

This document has been downloaded from Chalmers Publication Library (CPL). It is the author's version of a work that was accepted for publication in:

\section{IEEE Antennas and Propagation Society International Symposium, APSURSI 2016 - Proceedings}

Citation for the published paper:

Vosoogh, A. ; Kildal, P. (2016) "V-band high efficiency corporate-fed $8 \times 8$ slot array antenna with ETSI class II radiation pattern based on gap technology". 2016 IEEE Antennas and Propagation Society International Symposium, APSURSI 2016 - Proceedings pp. 803-804.

http://dx.doi.org/10.1109/APS.2016.7696110

Downloaded from: http://publications.lib.chalmers.se/publication/246435

Notice: Changes introduced as a result of publishing processes such as copy-editing and formatting may not be reflected in this document. For a definitive version of this work, please refer to the published source. Please note that access to the published version might require a subscription. 


\title{
V-band High Efficiency Corporate-Fed $8 \times 8$ Slot Array Antenna with ETSI Class II Radiation Pattern Based on Gap Technology
}

\author{
Abbas Vosoogh and Per-Simon Kildal \\ Department of Signals and Systems, Chalmers University of Technology \\ Gothenburg, Sweden \\ \{abbas.vosoogh, per-simon.kildal\}@ chalmers.se
}

\begin{abstract}
A multilayer gap waveguide $8 \times 8$ slot array antenna with high efficiency for $60 \mathrm{GHz}$ applications is presented in this paper. The proposed antenna is composed of three unconnected metal layers. A ridge gap waveguide corporate distribution network feeds a radiation layer with $4 \times 4$ cavity-backed slot subarrays. The co-polar radiation pattern and sidelobe levels of the antenna are improved by using a simple slot-tilting method to fulfill the radiation pattern requirement of the ETSI 302 standard for fixed radio links. The fabricated prototype has a relative bandwidth of $12 \%$ with input reflection coefficient better than $-10 \mathrm{~dB}$. The $\mathrm{E}$ - and H-planes radiation patterns satisfy the ETSI class II co-polar sidelobe envelope over 57-65 GHz frequency band. The measured total aperture efficiency is better than $65 \%$ over the operating frequency band.
\end{abstract}

Keywords-gap waveguide, high efficiency, cavity antenna array, mmilimeter wave, slot array antenna.

\section{INTRODUCTION}

Demand for low profile and low loss planar antennas for unlicensed $60 \mathrm{GHz}$ high data rate communication terminals is growing over the last few years. Several planar array antennas realized with different technologies such as: hollow rectangular waveguide by diffusion bonding of laminated thin copper plates [1], Substrate Integrated Waveguide (SIW) [2] and Substrate Integrated Cavity (SIC) [3] have been developed recently. Microstrip and SIW array antennas have lower efficiency due to dielectric loss than hollow waveguide slot arrays at millimeter wave frequencies. The gap waveguide technology is an alternative to these conventional guiding structures showing low loss and flexible manufacturing characteristics. Moreover, the electrical contact between the building blocks is not needed in this new guiding structure [4]. The wave propagation is controlled in desired directions by using soft/hard boundary conditions and a PEC/PMC stopband, i.e. the stopband appearing in the narrow gap between parallel PEC and PMC surfaces. In this paper we present a multilayer $8 \times 8$-element slot array antenna with high efficiency for the 60 $\mathrm{GHz}$ band. The purpose is to improve the radiation pattern of the antenna presented in [5]. The slots in the radiating layer are tilted $10^{\circ}$ to fulfill the sidelobe level requirement of the ETSI EN 302 standard for fixed radio links. Thereby the sidelobes in the principle planes of the array are not appearing in the E- and

This work has been financially supported by the Swedish Governmental Agency for Innovation Systems VINNOVA via a project within the VINN Excellence center Chase and the European Research Council (ERC) under the $7^{\text {th }}$ Framework Program ERC grant number 321125.

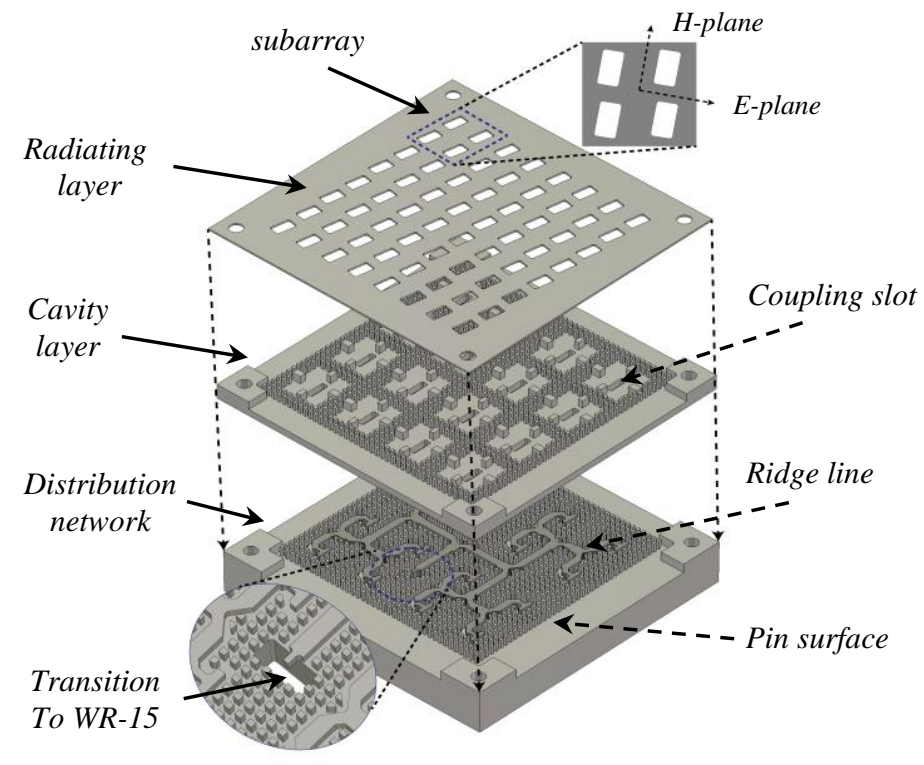

Fig. 1 Distributed view of the proposed corporate-fed $8 \times 8$ slot array antenna.

H-planes, assumed to correspond to horizontal and vertical planes. One of the advantages of the proposed antenna is that there is no need for electrical contact between the layers.

\section{ANTENNA CONFIGURATION AND DESIGN}

The confirmation of the proposed multilayer corporate-fed $8 \times 8$ slot array antenna is illustrated in Fig. 1. The antenna is made of $4 \times 4$ subarrays. Each subarray consists of an air-filled

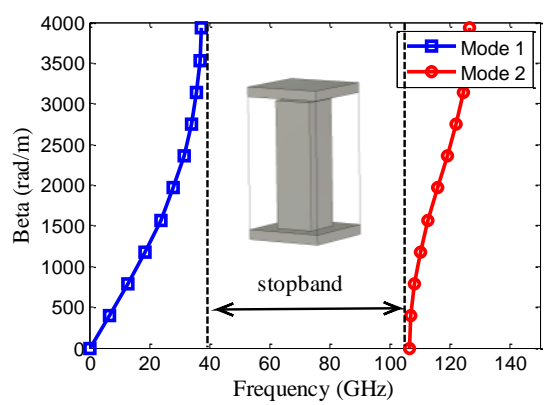

Fig. 2. Dispersion diagram for the infinite periodic pin unit cell. 

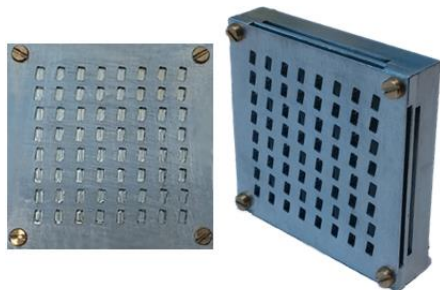

Fig. 3. Photograph of the fabricated $8 \times 8$ slot array antenna.

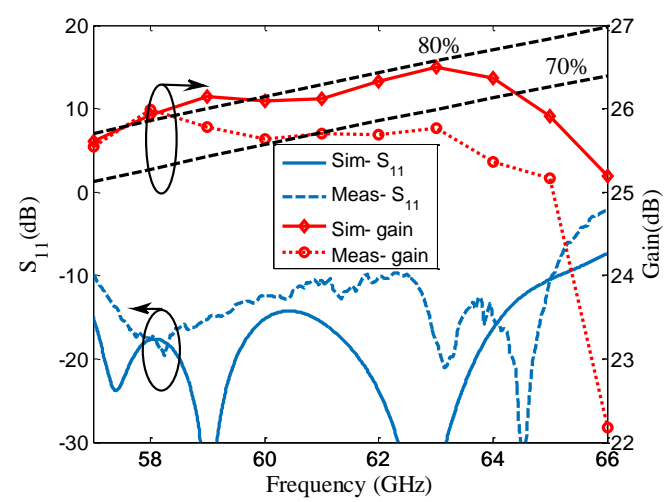

Fig. 4. Simulated and measured reflection coefficient and gain of the proposed $8 \times 8$ slot array antenna.

$2 \times 2$ cavity-backed slot formed by pins with spacing smaller, but close to one wavelength on the top layer. The designed subarray has $8 \times 8 \mathrm{~mm}^{2}$ dimension (the array unit cell). A ridge gap waveguide corporate distribution network feeds all subarrays with equal phase and amplitude via the coupling slots on the bottom layer. All three layers are separated with a small gap and no electrical contact between layers is needed. The pins in the top and bottom layers present a PEC/PMC stopband for the parallel-plate modes and suppress undesired modes and leakage. The pin dimensions have been suitably chosen to have the V-band well inside the stopband. The dispersion diagram of the pin unit cell used to create the stopband for the parallel plate modes is shown in Fig.2. A simple transition is designed to match the distribution network to WR-15 rectangular waveguide as shown in Fig.1. The radiating slots are tilted $10^{\circ}$ as explained in the introduction. The simulations are done by using CST Microwave studio.

\section{MEASURED RESULTS}

The fabricated $8 \times 8$ slot array antenna is shown in Fig. 3 . The total size of the antenna is $40 \times 40 \mathrm{~mm}^{2}$. The measured and simulated input reflection coefficient as well as the measured and simulated boresight gain of the prototype are shown in Fig. 4. The measured reflection coefficient is below $-10 \mathrm{~dB}$ within 57-65 GHz. The dashed lines show the maximum available directivities with $80 \%$ and $70 \%$ aperture efficiency. The measured total aperture efficiency of the antenna is better than $65 \%$ between 57 and $63 \mathrm{GHz}$. Fig. 5 shows the simulated and measured co-polar farfield patterns in E- and H-planes at 57 and $65 \mathrm{GHz}$. The co-polar sidelobes are below the ETSI EN 302 Class II standard envelope in both the E- and H-planes. The radiation patterns of the antenna presented in [5] are also shown for comparison. We see that the proposed slot-tilting method improves the radiation patterns of the antenna in E- and

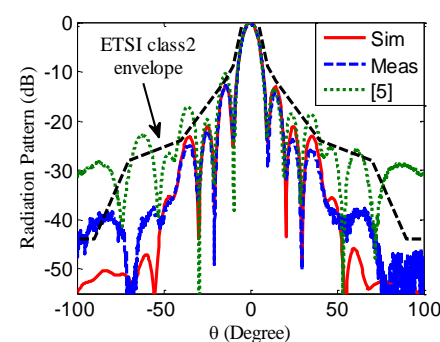

(a)

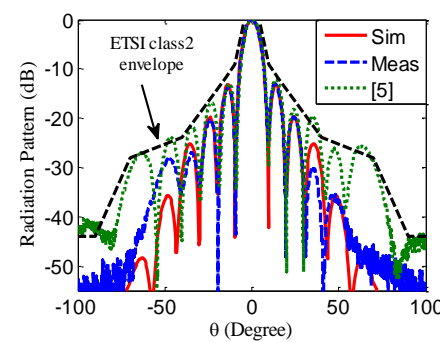

(c)

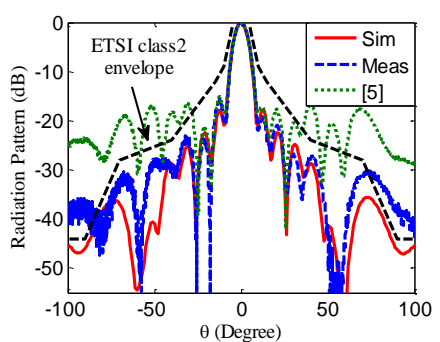

(b)

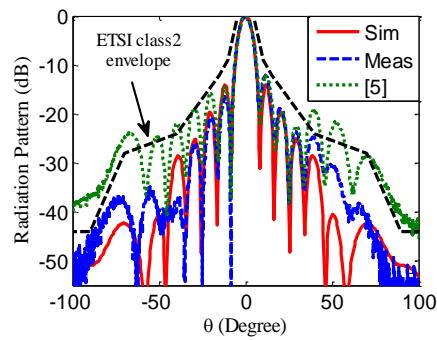

(d)
Fig. 5. Simulated and measured radiation patterns of the presented antenna and the previous antenna in [5]. (a) E-plane at $57 \mathrm{GHz}$, (b) H-plane at $57 \mathrm{GHz}$, (c) E-plane at $65 \mathrm{GHz}$, and (d) $\mathrm{H}$-plane at $65 \mathrm{GHz}$

H-planes. It is also worth to mention that the simulated crosspolar level of the proposed antenna is below $-28 \mathrm{~dB}$ in the operating band. There is good agreement between simulated and measured results except for a discrepancy between simulated and measured gain over most of the frequency range. We believe this is due to the outdoor measurement range and will repeat measurements in another range later.

\section{CONCLUSION}

We have presented a corporate-fed $8 \times 8$ slot array antenna with ETSI class II radiation pattern based on gap waveguide technology. The proposed antenna consists of three unconnected metal layers with a small gap between each layer. The proposed antenna shows better co-polar radiation patterns and lower sidelobe levels in E- and H-planes than the antenna presented in [5].

\section{References}

[1] Y. Miura, J. Hirokawa, M. Ando, Y. Shibuya and G. Yoshida, "Doublelayer full-corporate-feed hollow-waveguide slot array antenna in the 60GHz band," IEEE Trans. Antennas Propag., vol. 59, no. 8, pp. 28442851, Aug. 2011

[2] B. Cao, H. Wang, Y. Huang and J. Zheng, "High-gain L-prob exited substrate integrated cavity antenna array with LTCC-baced gap waveguide feeding network for W-band application," IEEE Trans. Antennas Propag., Sep. 2015.

[3] Y. Li and K-M. Lik, "60-GHz substrate integrated waveguide fed cavitybacked aperture-coupled microstrip patch antenna arrays," IEEE Trans. Antennas Propag., vol. 63, no. 3, pp. 1075-1085, March 2015.

[4] P. -S. Kildal, E. Alfonso, A. Valero-Nogueira, and E. Rajo-Iglesias, "Local metamaterial-based waveguides in gaps between parallel metal plates," IEEE Antenna Wireless Propag. Lett., vol. 8, pp. 84-87, Dec. 2009.

[5] A. Vosoogh and P.-S. Kildal, "Corporate-Fed Planar 60 GHz Slot Array Made of Three Unconnected Metal Layers Using AMC pin surface for the Gap Waveguide," IEEE Antenna Wireless Propag. Lett., Dec. 2015. 